Review

\title{
Porous Materials for Hydrolytic Dehydrogenation of Ammonia Borane
}

\section{Tetsuo Umegaki ${ }^{1, *}$, Qiang $X u^{2}$ and Yoshiyuki Kojima ${ }^{1}$}

1 Department of Materials \& Applied Chemistry, College of Science \& Engineering, Nihon University, 1-8-14 Kanda-Surugadai, Chiyoda-Ku, Tokyo 101-8308, Japan;

E-Mail: kojima.yoshiyuki@nihon-u.ac.jp

2 National Institute of Advanced Industrial Science and Technology (AIST), 1-8-31 Midorigaoka, Ikeda, Osaka 563-8577, Japan; E-Mail: q.xu@aist.go.jp

* Author to whom correspondence should be addressed; E-Mail: umegaki.tetsuo@nihon-u.ac.jp; Tel.: +81-3-3259-0810; Fax: +81-3-3293-7572.

Academic Editor: Umit B. Demirci

Received: 6 May 2015 / Accepted: 15 July 2015 / Published: 21 July 2015

\begin{abstract}
Hydrogen storage is still one of the most significant issues hindering the development of a "hydrogen energy economy". Ammonia borane is notable for its high hydrogen densities. For the material, one of the main challenges is to release efficiently the maximum amount of the stored hydrogen. Hydrolysis reaction is a promising process by which hydrogen can be easily generated from this compound. High purity hydrogen from this compound can be evolved in the presence of solid acid or metal based catalyst. The reaction performance depends on the morphology and/or structure of these materials. In this review, we survey the research on nanostructured materials, especially porous materials for hydrogen generation from hydrolysis of ammonia borane.
\end{abstract}

Keywords: hydrolysis of ammonia borane; porous materials; support; immobilization; nanostructured materials

\section{Introduction}

Sustainable energy is a priority and one of the most essential requirements on the global agenda in the 21 st century. Clean, effective, affordable and reliable energy is indispensable for global advancement 
and prosperity. The present energy system is based on the irreversible consumption of fossil resources. Due to their limited availability and environmental issues connected to their combustion, renewable sources of energy have drawn increasing attention in recent years. Seeking new and alternative energy sources has been one of the most difficult tasks because of the rise in prices to develop the energy sources, demands for fossil fuels, depletion or reduction of natural resources worldwide and fossil fuel reserves. Energy from many renewable sources, such as solar or wind power, cannot be gained on-demand and power is only supplied at specific times. For mobile applications, the energy has to be storable and transportable in a manner that can be handled easily and is efficient in terms of weight and volume. Faced with such obstacles, ways of storing energy from renewable sources become very interesting. Hydrogen has many advantages as an alternative energy carrier due to high energy density, and environmental friendliness [1-8]. The storage of electricity in the form of hydrogen suffers from penalties, especially from its low volumetric energy density. Production, storage and distribution of hydrogen from cheap and renewable sources with development of smart materials by using new technologies are the key factors for hydrogen energy utilization in real life. Hydrogen can be produced from chemical reactions [9], mainly from the reforming and thermal decomposition of hydrocarbons [10] in forms of liquid fuels (methanol, ethanol, gasoline, etc.). In this case, however, high-temperature reforming processes are too complex to satisfy the requirements of portable use. Alternative storage using chemical hydrides in the form of the liquid fuels could be employed as hydrogen sources. Among the chemical hydrides, ammonia borane is the most convenient material for a storage and supply system due to its advantages, such as high gravimetric/volumetric hydrogen storage capacity compared to other metal hydrides [11-20]. The compound has low molecular weight $\left(30.9 \mathrm{~g} \mathrm{~mol}^{-1}\right)$ and high hydrogen content of $19.6 \mathrm{wt} \%$ or $140 \mathrm{~g} \mathrm{~L}^{-1}$. Moreover, ammonia borane has a high solubility in water (33.6 g per $100 \mathrm{~mL}$ ) at room temperature and is stable in aqueous solution at room temperature [21-29]. Additionally, its non-toxic nature, non-flammability in basic aqueous solution, high stability in air, and the ability to control the hydrogen production can provide additional advantages. Moreover, the reaction co-product $\mathrm{NH}_{4} \mathrm{BO}_{2}$ can be recycled via an irreversible chemical reaction, in conjunction with off-board spent fuel regeneration [30], and hydrogen generation even at low temperatures can be possible with exothermic hydrolysis reactions. Ideal ammonia borane hydrolysis occurs according to the following reaction [31].

$$
\mathrm{NH}_{3} \mathrm{BH}_{3}+2 \mathrm{H}_{2} \mathrm{O} \rightarrow \mathrm{NH}_{4}^{+}+\mathrm{BO}_{2}^{-}+3 \mathrm{H}_{2}
$$

The hydrolysis reaction can be accelerated and controlled by the use of a suitable catalyst including noble or non-noble transition metals/their alloys or salts besides acid accelerators [32] from ammonia borane solution [33-48]. The catalyst activity is highly dependent on the metal species, particle size, crystal structure, catalyst precursor and support materials employed [16]. Preparation of a porous catalyst with large surface area can enhance the catalytic activity [49]. Porous materials have attracted great attention and undergone rapid development due to their adjustable pore structure and multifunctionality that can be achieved by tailoring the composition, structure, chemical composition, surface properties, and ability to adsorb/absorb [50].

In this review, we briefly survey the research progress in porous materials for hydrolysis of ammonia borane. 


\section{Porous Support Materials}

Support materials play not merely the role of carrier for active metal, but also provide a large active surface area and better dispersion of the active phase due to their porous nature. Besides that, a supported catalyst facilitates the diffusion of reactants through the pores to the active phase, which is the major limiting step for the hydrolysis reaction, improves the dissipation of the reaction heat, retards the sintering of the active phase, and increases the poison resistance. In comparison with various metals powder or their salt catalysts, the supported catalysts are highly appreciated in practical applications owing to their easy separation from fuel solution, and consequently, the ready controllability of the hydrolysis reaction and reusability of the catalyst [51,52]. In this section, we briefly survey porous support materials for supporting and immobilizing active species for hydrolysis of ammonia borane.

\subsection{Microporous and Mesoporous Inorganic Support Materials}

Porous materials are classified as macro-, meso- and microporous depending on the size of the pores, e.g., $>50 \mathrm{~nm}, 50-2 \mathrm{~nm}$ and $<2 \mathrm{~nm}$, respectively. The use of microporous and mesoporous materials with ordered porous structures as the hosts to encapsulate metal nanoclusters has attracted particular interest in catalysis because the pore size restriction could limit the growth of nanoclusters and lead to an increase in the percentage of the catalytically active surface atoms. The use of nanocluster catalysts in systems with confined void spaces such as inside mesoporous and microporous solids appears to be an efficient way of preventing aggregation [53-55].

Co and Co borides/phosphides show attractive catalytic activities [56,57]. The Co-B catalyst is supported on highly ordered mesoporous silica particles prepared by chemical impregnation-reduction method with pore size of 2-10 $\mathrm{nm}$ [58]. Co-B nanoparticles on the mesoporous silica are able to block large numbers of mesopores by either completely filling the pores from inside or positioning on the pore face, while Co-B particles supported on non-porous silica are composed of spherical particles in the range of 30-40 nm, all or part of which are present in agglomerated state. In contrast, mesoporous silica particle-supported Co-B affords a large amount of particles $(\sim 90 \%)$ having a size lower than $10 \mathrm{~nm}$. Co-B nanoparticles are located on the surface of the mesoporous silica particles with some portion of the former particles anchored into the pores. $\mathrm{Co}-\mathrm{B}$ catalyst supported on mesoporous silica particles was able to produce the expected amount of hydrogen $\left(\mathrm{H}_{2} / \mathrm{NH}_{3} \mathrm{BH}_{3}=3.0\right)$ by hydrolysis of ammonia borane, while unsupported $\mathrm{Co}-\mathrm{B}$ catalyst and that which is supported on non-porous silica particles were able to produce only $\sim 85 \%$ of $\mathrm{H}_{2}$ yield $\left(\mathrm{H}_{2} / \mathrm{NH}_{3} \mathrm{BH}_{3}=2.55\right)$. Hydrolysis in the presence of unsupported powder and $\mathrm{Co}-\mathrm{B}$ catalyst supported on non-porous silica particles is in the first order with respect to concentration of ammonia borane. By comparison, the hydrogen generation data produced by the Co-B catalyst supported on mesoporous silica particles powder was zero order with respect to ammonia borane concentration due to its high effective surface area that permits immediate hydrogen generation through surface reaction. The maximum hydrogen generation rate achieved with mesoporous silica particle-supported $\mathrm{Co}-\mathrm{B}$ is about 2.5 and 3 times higher than that obtained with non-porous silica particle-supported $\mathrm{Co}-\mathrm{B}$ and unsupported $\mathrm{Co}-\mathrm{B}$ powder catalyst.

The dispersion of the catalyst species depends on the types of mesoporous silica [55] (Figure 1). Co-B particles are located inside the pores of SBA-15 silica by keeping the pore structure intact while 
for MCM-41 and FSM-16 catalyst, particles either completely fill the pores or lie outside on the face of pores. The Co-B particles are well confined in the pores of SBA-15 acquiring the size of pores ( $\sim 6 \mathrm{~nm})$. Along the channel, the size of Co-B slightly increases to around $10 \mathrm{~nm}$. In case of FSM-16 and MCM-41, the $\mathrm{Co}-\mathrm{B}$ particles are well dispersed on the surface having broad distribution of size in the range from 3-30 nm, most of which (90\%) have a size lower than $15 \mathrm{~nm}$. A particle size greater than the pore size confirms that Co-B particles are located on the surface of the MCM-41 and FSM-16 type silica with some portion of the particle anchored into the pores. During the reduction process by sodium borohydride, the Co-B particles are formed by release of hydrogen gas. Due to the interconnected pore assembly, hydrogen can leave the interior of the SBA-15 easily. In FSM-16 and MCM-41, the pores are not connected and thus, hydrogen can be released only from the pore face which is blocked by the $\mathrm{Co}-\mathrm{B}$ particles. Thus, due to the pressure exerted by the hydrogen gas, the $\mathrm{Co}-\mathrm{B}$ particles are pushed out on the external surface of MCM-41 and FSM-16. The hydrogen production data for Co-B supported on all the mesoporous silica materials proves zero order kinetics with respect to concentration of ammonia borane. The maximum hydrogen generation rate achieved by $\mathrm{Co}-\mathrm{B}$ supported on SBA-15 silica $\left(\sim 1900 \mathrm{~mL}^{-\mathrm{H}_{2}} \mathrm{~g}-(\mathrm{Co}-\mathrm{B} \text { cat. })^{-1} \mathrm{~min}^{-1}\right)$ is 4.2 and 5.3 times higher than that obtained by non-porous silica supported $\mathrm{Co}-\mathrm{B}\left(\sim 480 \mathrm{~mL}-\mathrm{H}_{2} \mathrm{~g}-(\mathrm{Co}-\mathrm{B} \text { cat. })^{-1} \mathrm{~min}^{-1}\right)$ and unsupported $\mathrm{Co}-\mathrm{B}$ powder catalyst $\left(\sim 360 \mathrm{~mL}-\mathrm{H}_{2} \mathrm{~g}-(\mathrm{Co}-\mathrm{B} \text { cat. })^{-1} \mathrm{~min}^{-1}\right)$. For mesoporous silica supports, Co-B supported on SBA-15 showed the highest hydrogen generation rate which is about 1.5 times higher than that measured with MCM-41 $\left.\left(\sim 1150 \mathrm{~mL}-\mathrm{H}_{2} \text { g-(Co-B cat. }\right)^{-1} \mathrm{~min}^{-1}\right)$ and FSM-16 ( 1200 $\mathrm{mL}-\mathrm{H}_{2}$ g-(Co-B cat. $\left.)^{-1} \min ^{-1}\right)$. The activation energies of Co-B catalyst supported on SBA-15 $\left(43 \mathrm{~kJ} \mathrm{~mol}^{-1}\right)$ displays significantly lower energy barriers in comparison to Co-B supported on MCM-41 $\left(51 \mathrm{~kJ} \mathrm{~mol}^{-1}\right)$ and FSM-16 $\left(58 \mathrm{~kJ} \mathrm{~mol}^{-1}\right)$.
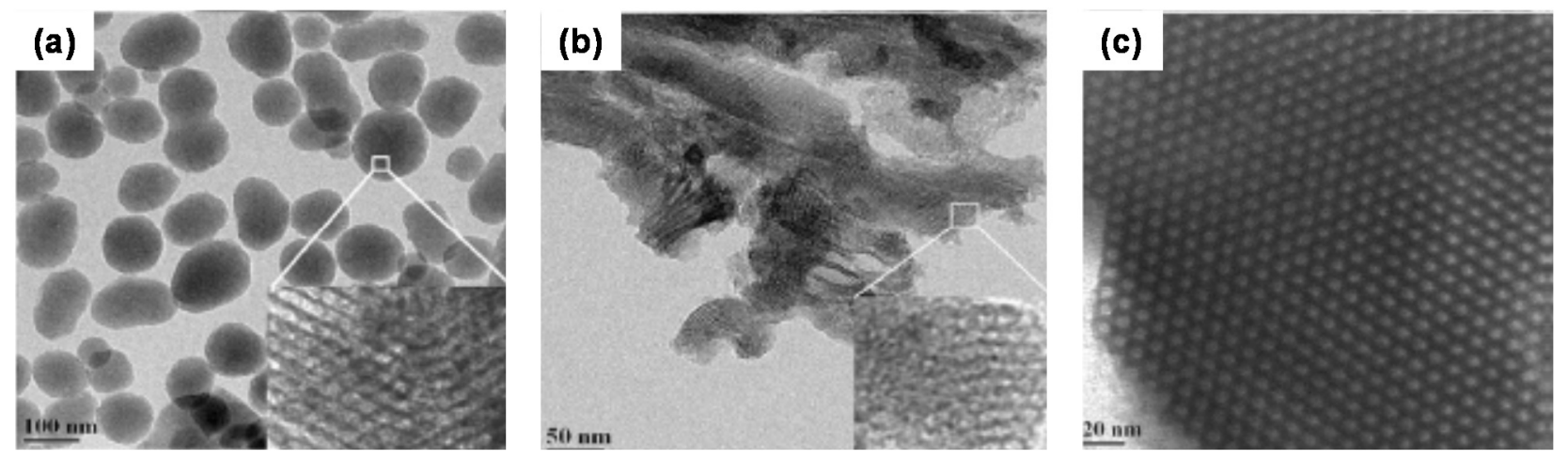

Figure 1. TEM micrograph of MCM-41 (a); FSM-16 (b); and SBA-15 (c). Reproduced with permission of Ref. [55].

Co-B catalysts were also synthesized by pulsed laser deposition (PLD) in form of nanoparticle-assembled films because of easily controllable surface morphology and structure by the use of this method $[22,59,60]$. Nanoparticle-assembled Co-B thin film on a planar glass substrate was able to produce almost the expected amount of hydrogen (95\%) from hydrolysis of ammonia borane with significantly higher rate (about six times) than the same amount of the corresponding Co-B powders [60]. The Co-B nanoparticles were produced during the ablation process on the film surface, with an average size of around $\sim 250 \mathrm{~nm}$ and well established spherical form. Highly irregular and porous carbon film was adopted as a support for the Co-B nanoparticles to effectively improve the initial surface area and obtain better dispersion of nanoparticles. The films ranging from diamond-like to highly porous, 
cluster-assembled structures were deposited using PLD by varying laser parameters [61]. The total amount of hydrogen generated by hydrolysis of ammonia borane using both the Co-B films $\left(\mathrm{H}_{2} / \mathrm{NH}_{3} \mathrm{BH}_{3}=2.85\right)$ is closer to the quantitative yield expected from the reaction stoichiometry $\left(\mathrm{H}_{2} / \mathrm{NH}_{3} \mathrm{BH}_{3}=3.0\right)$ than that generated by $\mathrm{Co}-\mathrm{B}$ powder $\left(\mathrm{H}_{2} / \mathrm{NH}_{3} \mathrm{BH}_{3}=2.55\right)$. The maximum hydrogen generation rate obtained for the carbon-supported Co-B films $\left(\sim 4060 \mathrm{~mL}-\mathrm{H}_{2} \mathrm{~g}_{\text {-cat. }}{ }^{-1} \mathrm{~min}^{-1}\right)$ has been found to be significantly higher than that obtained using the unsupported $\mathrm{Co}-\mathrm{B}$ film ( $\sim 2400 \mathrm{~mL}-\mathrm{H}_{2}$ g-cat. $^{-1} \mathrm{~min}^{-1}$ ) [62]. Both unsupported and supported Co-B catalyst films synthesized by PLD showed amorphous spherical particle-like morphology (average size ranging between 50 and 300 $\mathrm{nm}$ ) with some agglomerates. The supported $\mathrm{Co}-\mathrm{B}$ film had a dendritic microstructure with the $\mathrm{Co}-\mathrm{B}$ nanoparticles embedded in the porous carbon film with improved dispersion. By comparison, the carbon film deposited at low Ar pressure exhibited a columnar structure with embedded spherical nodules on the surface. By increasing the pressure, dendritic, highly porous microstructure starts to appear with extremely irregular surface features which appear bigger, more loosely packed, and non-spherical with barely any adhesion to the substrate because cluster-cluster collision may also occur. Film-substrate adhesion is slightly poorer than that reached at low Ar pressure. Co-B catalysts supported on the carbon film deposited at low Ar pressures show almost similar catalytic activity as unsupported Co-B film due to the non-porous structure of the carbon films. However, the catalytic activity increases for Co-B catalysts supported on the carbon films deposited at higher Ar pressures. Hydrogen generation rate reached the maximum for the carbon film deposited at low pressure (40 Pa), and then, Co-B catalyst supported on the carbon film deposited at highest pressure of $50 \mathrm{~Pa}$ showed drastic decrease in the hydrogen generation rate and was not able to complete the hydrolysis reaction of ammonia borane due to its very weak adhesion with the substrate that leads to slow detachment of the film from the substrate in the reactant solution. The activation energy of the carbon film supported Co-B film is $29 \mathrm{~kJ} \mathrm{~mol}^{-1}$ which is lower than that obtained with unsupported $\mathrm{Co}-\mathrm{B}$ film $\left(34 \mathrm{~kJ} \mathrm{~mol}^{-1}\right)$ and $\mathrm{Co}-\mathrm{B}$ powder $\left(44 \mathrm{~kJ} \mathrm{~mol}^{-1}\right)$ [62].

$\mathrm{Ni}$ foam-supported amorphous ternary catalysts such as $\mathrm{Co}-\mathrm{Mo}-\mathrm{B}$ and $\mathrm{Co}-\mathrm{W}-\mathrm{B}$ have been prepared by a modified electroless plating method and exhibited enhanced hydrogen generation kinetics $[58,63]$. In a typical electroless deposition case, hydrogen evolution as a by-product is deliberately inhibited in order to produce a uniform and dense metallic coating by using strong complex agents and stabilizers in the bath solution. In the modified method, the formation of gas by increasing the concentrations of reducing agent and main salts, as well as elimination of the use of stabilizer was favored, and then, the nucleation and deposition rates of the metals are greatly increased, and a large number of hydrogen bubbles are evolved. These hydrogen bubbles function as a dynamic template and metal is chemically deposited and grows within the interstitial spaces between the hydrogen bubbles forming a porous coating of metallic particles on the support. Quaternary cobalt-tungsten-boron-phosphorus porous particles supported on $\mathrm{Ni}$ foam $(\mathrm{Co}-\mathrm{W}-\mathrm{B}-\mathrm{P} / \mathrm{Ni})$, which are prepared through ultrasonification-assisted electroless deposition route, consisted of interconnected flower-like porous nanospheres (diameters: 200-400 nm) with enhanced contact between the active component and the substrate [64]. The molar ratio of generated hydrogen to the initial ammonia borane was close to 3.0, and the required reaction time with $\mathrm{Co}-\mathrm{W}-\mathrm{B}-\mathrm{P} / \mathrm{Ni}$ was much shorter than that with $\mathrm{Co}-\mathrm{W}-\mathrm{B} / \mathrm{Ni}$ and $\mathrm{Co}-\mathrm{B} / \mathrm{Ni}$. The catalytic hydrolysis reaction with respect to ammonia borane concentration exhibited quasi first-order character. Hydrogen generation rate in the presence of the most active catalyst was $4000 \mathrm{~mL}-\mathrm{H}_{2} \mathrm{~g}_{-} \mathrm{cat}^{-1} \mathrm{~min}^{-1}$. 
Moreover, the apparent activation energy for the quaternary catalyst was determined to be $29.0 \mathrm{~kJ} \mathrm{~mol}^{-1}$. After the 10th usage, the catalyst preserved $68 \%$ of its original hydrogen generation rate. The deposited catalyst layer did not peel off from the Ni foam substrate after repeated testing.

The use of zeolites as host materials with confined void spaces for guest metal nanoparticles seems to be one of the up-and-coming strategies to prevent the agglomeration of metal nanoparticles and bulk metal formation. Furthermore, encapsulation of metal nanoparticles within the porous structure of zeolite or between the zeolite-supported layers can help in the kinetic control of catalytic reactions [65].

Ru nanoparticles@ZK-4 were prepared by ion-exchange of $\mathrm{Ru}^{3+}$ ions with the extra framework $\mathrm{Na}^{+}$ cations of ZK-4 zeolite $\left(\mathrm{Na} 9\left[\left(\mathrm{AlO}_{2}\right)_{9}\left(\mathrm{SiO}_{2}\right)_{15}\right] \cdot 27 \mathrm{H}_{2} \mathrm{O}\right)$, LTA type structure (Linde-type A, Figure 2) with highly ordered cavities in 3-D structure, following sodium borohydride reduction of ruthenium(III)-exchanged ZK-4 in water at room temperature [66]. Neither the crystallinity nor the lattice of ZK-4 zeolite is altered by ion exchange. The incorporation of ruthenium(III) ions into ZK-4 zeolite and the reduction of ruthenium(III) ion forming Ru nanoparticles@ZK-4 causes no observable alteration in the framework lattice and no loss in the crystallinity of ZK-4 zeolite. Well dispersed ruthenium metal nanoparticles were present on the external surface of zeolite. The particle size of ruthenium nanoparticles was found to be in the range of 2.0-3.7 nm with a mean diameter of $2.9 \mathrm{~nm}$. On passing from ZK-4 zeolite to ZK-4 zeolite and Ru nanoparticles@ZK-4, a notable decrease in the micropore volume and micropore area are observed, indicating that ruthenium nanoparticles exist not only on the surface but also inside the cavities of ZK-4 zeolite. The initial rates of hydrogen generation from the hydrolysis of ammonia borane are the highest using Ru nanoparticles@ZK-4 containing $1.1 \mathrm{wt} . \% \mathrm{Ru}$, mostly on the surface and readily accessible. They provide the complete stoichiometric hydrogen generation $\left(\left[\mathrm{H}_{2}\right] /\left[\mathrm{H}_{3} \mathrm{NBH}_{3}\right]=3\right)$ at $293 \mathrm{~K}$. The activation energy was $28.2 \mathrm{~kJ} \mathrm{~mol}^{-1}$ and the turnover frequency (TOF) of Ru nanoparticles@ZK-4 was 5400 mol- $\mathrm{H}_{2}$ mol- $\mathrm{Ru}^{-1} \mathrm{~h}^{-1}$. The complete release of hydrogen is achieved in each of the successive catalytic runs ( 5 runs) without leaching of ruthenium into the reaction solution. The decrease $(<15 \%)$ in catalytic activity in subsequent runs can be attributed to the passivation of active nanoparticle surfaces by boron products, e.g., metaborate, which decreases accessibility of active sites as previously seen in the case of $\mathrm{Rh}(0)$ nanoparticles@zeolite [36] and Cu(0) nanoparticles@zeolite [65].

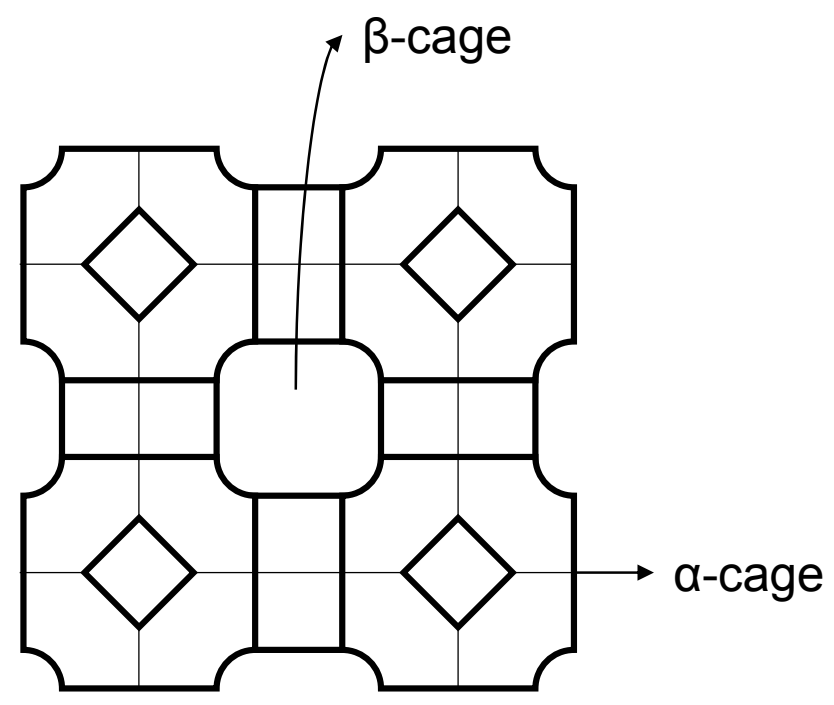

Figure 2. The framework structure of ZK-4 zeolite with $\alpha$ - and $\beta$-cage [66]. 
Three-dimensional graphene-based framework (3DGF) like foams, sponges, and aerogels consist of exfoliated graphene sheets with lateral dimensions of several micrometers and an interconnected framework of ultrathin graphene nanosheets with porous structure (pore size: from a few hundred nanometers to several micrometers). Three-dimensional nitrogen-doped graphene-based frameworks (3D-(N)GFs) were synthesized using dicyandiamide as the nitrogen precursor, via a hydrothermal reaction and freeze-drying process. 3D-(N)GFs consist of three types of nitrogen: pyridinic nitrogen $\mathrm{N}$ (N1), pyrrolic nitrogen N (N2), and graphitic nitrogen N (N3). From the Raman spectrum, the slight upshift of the D and G bands of 3D-(N)GFs were observed because of the structural distortion of graphene induced by the different bond distances of $\mathrm{C}-\mathrm{C}$ and $\mathrm{C}-\mathrm{N}$ after doping. $\mathrm{Ni}^{2+}$ was introduced to the 3D-(N)GFs and subsequently reduced with sodium borohydride to obtain metallic nickel nanoparticles immobilized in three-dimensional nitrogen-doped graphene-based frameworks (NiNPs@3D-(N)GFs) [67]. Nanoparticles $(2-4 \mathrm{~nm})$ dispersed on the surface of the 3D-(N)GFs were obtained. At a relatively low pressure, appreciable decreases in nitrogen adsorption were observed for the Ni-loaded three-dimensional nitrogen-doped graphene based frameworks when compared with pristine graphene oxide, which can be interpreted by the existence of nickel nanoparticles on the graphene surface. With an increasing nitrogen content, the catalytic performance for hydrolysis of ammonia borane increases, and NiNPs@3D-(N)GFs with nitrogen content of $3.7 \%$ shows the highest activity. The incorporation of nitrogen strengthens the metal-support interactions and the effective immobilization of metal nanoparticles. Moreover, nitrogen doping leads to an increase in the surface chemical activity in terms of polarity and basicity. The activity in terms of TOF is $41.7 \mathrm{~mol}-\mathrm{H}_{2} \mathrm{~mol}-\mathrm{Ni}^{-1} \mathrm{~min}^{-1}$ for the as-synthesized NiNPs@3D-(N)GFs. The catalyst also shows good stability for recycle tests. The activation process occurs on the metal catalyst surface, as suggested by the zero order kinetics.

\subsection{Polymer Gels for Support or Immobilization of Active Species}

The design of advanced polymeric materials with controllable size, charge, functionality and porosity has great significance in obtaining efficient composites for use in hydrogen generation [68]. Nanocomposites containing polymer and inorganic particles have very good advantages for the preparation of artificial membranes with excellent separation performances, good thermal and chemical stability and adaptability to the harsh environments, as well as membrane forming ability [69-72].

Hydrogels are insoluble three-dimensional cross-linked hydrophilic polymeric materials. As the size of the hydrogel can be tuned from bulk to micro and/or nanometer, the pore size can also be designed as microporous, mesoporous and super porous up to a few micrometers [68]. Microgels are generally described as hydrogels with crosslinked polymeric particles below $100 \mathrm{~nm}$ that can be swollen by a good solvent. The high water content of microgels makes them soft and elastic with increased and tunable physical characteristics and these properties provide great resemblance to soft tissues $[73,74]$. Using silica precursors during microgel particle preparation allows composite material synthesis with adaptable surface and pore structure as silica particles are dissolvable via $\mathrm{NaOH}$ or HF treatments [75]. There has been an increased interest in using microgels as microreactors for templated synthesis of inorganic and/or metal nanoparticles [76]. Cryogels are sponge-like macroporous hydrophilic materials prepared by cryo-polymerization of monomers in the presence of ice crystals under frozen 
conditions [77,78]. Generally, cryogels are prepared by a free radical cryopolymerization reaction carried out at temperatures below $273 \mathrm{~K}$, in the presence of a highly aqueous system containing monomers, cross-linker, and initiator. Upon the polymerization of the nonfrozen phase, 3-D gel formation occurs around the growing ice crystals which act as a template for the formation of the pores. Due to the crosslinking of polymer-polymer chains, a stable structure with macroporous gel network is revealed upon melting of the ice crystals at room temperature $[79,80]$.

The use of cryogels in various catalytic reaction can offer additional advantages such as fast diffusion of the chemicals. Highly porous p(2-hydroxyethyl methacrylate) p(HEMA) cryogels were synthesized via cryopolymerization technique and used as templates for $\mathrm{Co}, \mathrm{Ni}$, and $\mathrm{Cu}$ nanoparticle preparation [81]. The size of metal nanoparticles within porous cryogel matrices was found to be 100-200 nm. The TOF values of $\mathrm{p}(\mathrm{HEMA})-\mathrm{Co}, \mathrm{Ni}$ and $\mathrm{Cu}$ were $3.8,0.8$ and $1.1 \mathrm{~mol} \mathrm{H}_{2}$ mol-cat. ${ }^{-1} \mathrm{~min}^{-1}$ for hydrolysis of ammonia borane and the activation energy of the most active p(HEMA)-Co was $37.0 \mathrm{~kJ} \mathrm{~mol}^{-1}$. In every use, $100 \%$ conversion was obtained, while activity gradually decreased from $100 \%-57.7 \%$ at the end of the fifth use. The metal nanoparticles within poly(3-sulfopropyl methacrylate) (p(SPM)) cryogels are evenly distributed with a size of about few hundred $\mathrm{nm}$ in $\mathrm{p}(\mathrm{SPM})-\mathrm{M}(\mathrm{M}$ : $\mathrm{Co}, \mathrm{Ni}$, and $\mathrm{Cu}$ ) composite cryogels [82]. The pore sizes of $\mathrm{p}(\mathrm{SPM})$ cryogel are a few tens of micrometers. The hydrogen generation rates for $\mathrm{Co}, \mathrm{Ni}$, and $\mathrm{Cu}$-loaded cryogels for the hydrolysis reaction of ammonia borane were 2469, 1591, and $700 \mathrm{~mL}-\mathrm{H}_{2}$ g-metal ${ }^{-1} \mathrm{~min}^{-1}$, respectively. The activation energies for hydrolysis of ammonia borane catalyzed by poly(vinyl imidazole)-Co capsule particles were reported as $51.6 \mathrm{~kJ} \mathrm{~mol}^{-1}[83]$, and $25.6 \mathrm{~kJ} \mathrm{~mol}^{-1}$ for $\mathrm{p}(\mathrm{SPM})$-Co cryogel composite systems.

Poly(vinyl phosphonic acid) (p(VPA)) microparticle and composite $\mathrm{p}(\mathrm{VPA})$-silica microparticle hydrogels are synthesized using a micro-emulsion polymerization technique. P(VPA) hydrogel with macro dimensions were shown for use as template in the preparation of metal nanoparticles such as Co, $\mathrm{Ni}$, and $\mathrm{Cu}[84,85]$. The preparation of $\mathrm{p}(\mathrm{VPA})$ in a smaller dimension can offer better catalytic performance for their in situ prepared metal nanoparticles and tunable porosities by inclusion of silica moieties. $\mathrm{P}(\mathrm{VPA})$ microgels synthesized with $N, N^{\prime}$-methylenebisacrylamide (MBA) crosslinker are spherical in shape. The particle sizes vary from a few hundred $\mathrm{nm}$ to $20 \mathrm{~mm}$. To generate additional pores in $\mathrm{p}$ (VPA) microgels, the prepared $\mathrm{p}$ (VPA)-Si composite was treated with $0.5 \mathrm{M} \mathrm{NaOH}$ to remove the silica particles. Metal nanoparticles, $\mathrm{Co}, \mathrm{Ni}$, and $\mathrm{Cu}$ are generated in situ inside these hydrogels by chemical reduction of the absorbed metal ions with a reducing agent such as sodium borohydride. The hydrogen generation rates for $\mathrm{Co}, \mathrm{Ni}$, and $\mathrm{Cu}$-loaded microgels for hydrolysis of ammonia borane were 3272,1538 , and $433 \mathrm{~mL}-\mathrm{H}_{2}$ g-metal ${ }^{-1} \mathrm{~min}^{-1}$, respectively. The activation energy for hydrolysis of ammonia borane catalyzed by $\mathrm{p}$ (VPA)-Co microgels was $25.5 \mathrm{~kJ} \mathrm{~mol}^{-1}$. The conversion was $100 \%$ until the end of the third use, and reduced to $90 \%$ at the end of the 10th use. The catalytic activity of bulk $\mathrm{p}$ (VPA)-Co is significantly reduced to $15 \%$ after the fifth use, whereas, $\mathrm{p}$ (VPA)-Co microgel has very good catalytic activity and performance. Hydrogen generation rates for porous $\mathrm{p}$ (VPA)-Co and p(VPA)-Co microgels were 2033 and $1407 \mathrm{~mL}-\mathrm{H}_{2} \mathrm{~g}_{-} \mathrm{Co}^{-1} \mathrm{~min}^{-1}$, respectively. Accordingly, the porosity in the microgel can generate high metal ion loading capacity, and fast hydrogen production rates. P(VPA) microgels have pore sizes of $17.4 \mathrm{~nm}$, whereas $\mathrm{p}(\mathrm{VPA})-\mathrm{Si}$ and porous $\mathrm{p}(\mathrm{VPA})$ microgels have 25.1 and $60.2 \mathrm{~nm}$ pore sizes, respectively. 


\subsection{Metal-Organic Frameworks for Immobilization of Active Species}

Metal-organic frameworks (MOFs) synthesized by assembling metal ions with organic ligands have recently emerged as a new class of porous materials for their amenability to design as well as fine-tunable and uniform pore structures. Their distinct characteristics make them very promising for a variety of applications, including gas storage and separation, sensing, optics, drug delivery, and catalysis [86-97]. By serving as unique host matrices, the potential applications of MOFs can be extended further by encapsulating metal nanoparticles within the frameworks. MOFs have been utilized as supports for metal nanoparticles since they provide a powerful confinement effect to limit the growth of metal nanoparticles. However, the precursor compounds and products can actually diffuse out through the pores of the host to form the metal nanoparticles with aggregation on the external surface of MOFs. To circumvent these drawbacks, great efforts have been made.

The MOF compound, $\mathrm{Co}$ (bdc)2(dabco) (bdc = 1,4-benzenedicarboxylate; dabco = 1,4-diazabicyclo[2.2.2] octane), is used as the precursor to synthesize a catalyst with dispersed $\operatorname{Co}(0)$ metal sites [98]. The catalytically effective $\operatorname{Co}(0)$ sites are stabilized by the organic molecules, which are used to coordinate to Co (II) in the MOF precursor. The precursor of Co-MOF has a 3-D pillared structure with an accompanying 3-D pore system. When ammonia borane is added to a mixture of Co-MOF and sodium borohydride, the framework of Co-MOF collapses and the amorphous $\operatorname{Co}(0)$ catalyst is formed in situ through the reduction of the Co-MOF. The resulting catalytically active $\mathrm{Co}(0)$ sites are separated by the residue of the precursor of Co-MOF and stabilized by the organic linkers. A hydrogen generation rate of $932,000 \mathrm{~mL}-\mathrm{H}_{2}$ mol-cat ${ }^{-1} \mathrm{~min}^{-1}$ was obtained in $0.32 \mathrm{M}$ ammonia borane. $\mathrm{Co}(\mathrm{OH})_{2}$ is formed during the reaction and deposited on the surface of the catalyst when it is exposed to air, resulting in a significant decrease in catalytic activity.

ZIF-8 was demonstrated to have a strong ability in immobilizing Ni nanoparticles, preventing their aggregation and therefore increasing their catalytic surface area [99]. Highly dispersed Ni NPs immobilized on ZIF-8 (Ni/ZIF-8) have been prepared and their catalytic activity studied for hydrolysis of ammonia borane. A small volatile molecule nickelocene $\mathrm{Ni}(\mathrm{cp})_{2}$ was used as a precursor of $\mathrm{Ni}$ nanoparticles. ZIF-8 incorporating $\mathrm{Ni}(\mathrm{cp})_{2}\left[\mathrm{Ni}(\mathrm{cp})_{2} / \mathrm{ZIF}-8\right]$ were synthesized via chemical vapor deposition and chemical liquid deposition and subjected to reduction by $\mathrm{H}_{2} / \mathrm{Ar}$ at $573 \mathrm{~K}$ with different $\mathrm{Ni}$ loadings. The most active sample was a CVD-Ni/ZIF-8 sample in which Ni nanoparticles were highly dispersed

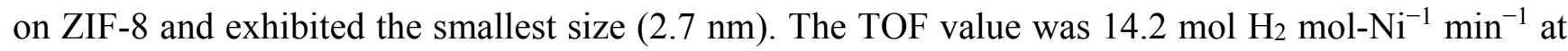
room temperature. No significant decrease in catalytic activity was observed even after five consecutive hydrolysis reactions.

Ultrafine metallic Pt nanoparticles have been supported onto MIL-101(Cr) without aggregation on the external surface (Figure 3) and their catalytic activity has been investigated [46]. Pt@MIL-101(Cr) with Pt loadings up to $5 \mathrm{wt}$. \% exhibits the same crystallinity as the parent MIL-101(Cr), indicating that the integrity of the MIL-101 framework was maintained during the preparation procedure. 2 wt. \% Pt@MIL-101(Cr) exhibited a uniform distribution of Pt nanoparticles of 1.2-3 nm (average $1.8 \mathrm{~nm}$ ) in the MIL-101(Cr) framework. The Pt@MIL-101(Cr) required 2.5 min to complete the hydrolysis of ammonia borane which corresponds to $\sim 1.0 \times 10^{7} \mathrm{~mL}-\mathrm{H}_{2} \mathrm{~mol}_{-\mathrm{Pt}^{-1}} \mathrm{~min}^{-1}$ at room temperature. Pt@MIL-101(Cr) was reused for five runs with no significant drop in its activity and no changes in the MIL-101(Cr) framework or in the morphology of Pt nanoparticles was observed. 


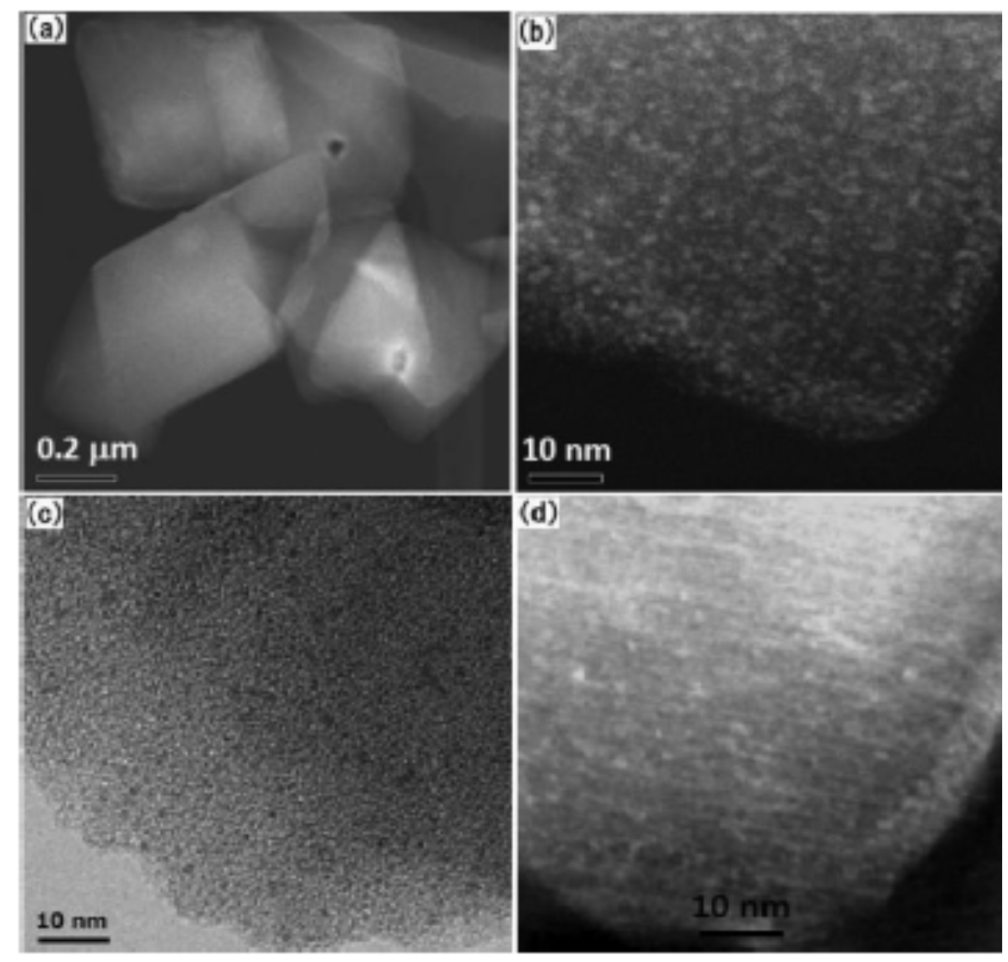

Figure 3. (a,b) HAADF-STEM; (c) TEM images; and (d) reconstructed slice by tomography of 2 wt. \% Pt@MIL-101. Reproduced with permission of Ref. [46]. Copyright 2012 American Chemical Society.

Alloying a parent metal with a second metal offers numerous opportunities for modulating the electronic structures of catalysts and optimizing their catalytic performance $[100,101]$. When the noble metal precursors are loaded, they can be treated by the hydrogen and plasma reduction methods under relatively moderate conditions which are suited perfectly for the preparation of noble nanoparticles hosted inside the MOFs [46], but not for non-noble metal based nanoparticles because of contradictions between the high reduction temperatures of non-noble metals and the low thermal stabilities of MOFs. Therefore, a general and facile method that can easily control the nucleation and growth of metal nanoparticles, especially non-noble metal-based nanoparticles, with high uniformity only inside the pores of MOF is still imperative. A double solvents method introduced noble metal precursors into the MOF pores without metal nanoparticle aggregation on the external framework surface after the precursors underwent hydrogen reduction at a relatively low temperature [46]. However, the hydrogen reduction method is not suited for non-noble metal precursors because of contradictions between the high reduction temperatures of non-noble metals and the limited thermal stabilities of MOFs. To circumvent this drawback, an overwhelming reduction approach in solution at room temperature were exploited which could encapsulate the non-noble metal nanoparticles within the MOF pores [102].

AuNi alloy nanoparticles have been immobilized onto the pores of MIL-101(Cr), a chromium-based MOF with molecular formula $\mathrm{Cr}_{3} \mathrm{~F}\left(\mathrm{H}_{2} \mathrm{O}\right)_{2} \mathrm{O}\left[\left(\mathrm{O}_{2} \mathrm{C}\right) \mathrm{C}_{6} \mathrm{H}_{4}\left(\mathrm{CO}_{2}\right)\right]_{3} \cdot n \mathrm{H}_{2} \mathrm{O}$ (where $n=\sim 25$ ) [103]. MIL-101 has incredibly large pore size $(2.9-3.4 \mathrm{~nm})$ and high specific surface area $\left(5900 \mathrm{~m}^{2} \mathrm{~g}^{-1}\right)$. The pore windows with diameters of $\sim 1.2$ and $1.6 \mathrm{~nm}$ are big enough for the precursor compounds $\mathrm{HAuCl}_{4}$ and $\mathrm{NiCl}_{2}$ to diffuse into the pores, within which nucleation can take place to form the AuNi alloy nanoparticles. Because of the large inner surface area of MIL-101 with hydrophilic character derived 
from the metal-cluster based trimeric building block, the small amount of aqueous precursor solution, with a volume slightly less than the pore volume of the adsorbent, was readily incorporated into the pores of dehydrated MIL-101, which was suspended in a large amount of dry n-hexane, by capillary force. After loading the precursors and drying the metal precursor/MOF composite, an overwhelming reduction approach with a high-concentration of sodium borohydride solution was carried out for avoiding metal nanoparticle aggregation on external surfaces of MIL-101 framework. When a high-concentration of sodium borohydride solution (0.6 M) is used, highly dispersed AuNi alloy nanoparticles with average size of $1.8 \mathrm{~nm}$ were encapsulated within the pores of MIL-101 without deposition on the external surface. No large particle aggregation and uniform 3D distribution of monodispersed AuNi nanoparticles throughout the interior cavities of MIL-101 crystals was observed. After the impregnation and reduction processes, there is no loss of the crystallinity for AuNi@MIL-101, indicating that the integrity of the MIL-101 framework is maintained. The appreciable decreases in the surface areas and the pore volumes of M@MIL-101 indicate that the pores of the host frameworks are occupied by dispersed metal nanoparticles and/or blocked by the metal nanoparticles located on the surface.The AuNi@MIL-101 catalysts are more active for the hydrolysis of ammonia borane than the monometallic counterparts, exhibiting a synergistic effect between Au and Ni. The AuNi@MIL-101 with the $\mathrm{Au} / \mathrm{Ni}$ atomic ratio of 7:93 shows a TOF of $66.2 \mathrm{~mol}-\mathrm{H}_{2}$ mol-cat ${ }^{-1} \mathrm{~min}^{-1}$. The productivity of hydrogen over the AuNi@MIL-101 catalyst remained almost unchanged after five runs. Since the degenerative performance can be recovered totally after catalyst recycling, the slight activity drop should be attributed to the increase in concentration of metaborate and the viscosity of the solution during the hydrolysis of ammonia borane. Once metaborate generated during the reaction was removed from solution, the catalyst exhibited its original catalytic activity. No significant change in the morphologies of AuNi nanoparticles was observed along with retention of the MIL-101 framework were observed.

Ultrafine AuCo alloy nanoparticles were also encapsulated in the pores of MIL-101 without aggregation on the external surfaces of the host framework by using the double solvents method combined with the overwhelming reduction approach [103]. Highly dispersed and homogeneous AuCo alloy particles with size of $c a .1 .8 \mathrm{~nm}$ were formed in the MIL-101 framework. The BET surface areas of MIL-101 and AuCo@MIL-101 are 3452 and 1930 m $^{2} \mathrm{~g}^{-1}$, respectively. The AuCo@MIL-101 with

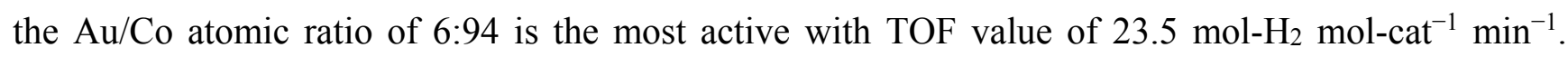
There was no significant decrease in catalytic activity even after five runs of hydrolysis reactions for the catalysts. No significant change in the morphologies of AuCo NPs were observed, along with retention of the MIL-101 framework.

Table 1 lists particle sizes and TOF of various catalysts discussed in this section. From this table, TOF of various catalysts appear to depend not only on the particle size, but also on other factors such as the particle dispersion, and metal-support interaction. Effective porous materials with high activity for hydrolytic dehydrogenation of ammonia borane are MOF, zeolite, and graphene nanosheet. Especially, uniform distribution of metal nanoparticles without aggregation after catalysis confirms the advantage of metal nanoparticles within the MOF matrix. 
Table 1. Particle size of active species and turnover frequency (TOF) of various catalysts.

\begin{tabular}{|c|c|c|c|c|}
\hline Catalysts & Active Species & Particle Size (nm) & TOF (mol-H min $^{-1}$ mol-Active Species ${ }^{-1}$ ) & Ref. \\
\hline Co-B/SBA-15 & $\mathrm{Co}-\mathrm{B}$ & $6-12$ & 3.4 & {$[55]$} \\
\hline Co-B/MCM-41 & - & $3-30$ & 2 & - \\
\hline Co-B/FSM-16 & - & $3-30$ & 2.1 & - \\
\hline Co-B/non-porous & - & 30 & 0.9 & - \\
\hline unsupported $\mathrm{Co}-\mathrm{B}$ & - & $30-40$ & 0.6 & - \\
\hline Co-B/C-film & - & $50-300$ & 0.6 & [62] \\
\hline unsupported Co-B film & - & $\sim 250$ & 0.1 & - \\
\hline $\mathrm{Co}-\mathrm{W}-\mathrm{P}-\mathrm{B} / \mathrm{Ni}$ foam & - & $200-400$ & - & [64] \\
\hline Ru@ZK-4 & $\mathrm{Ru}$ & 2.9 & 90 & {$[66]$} \\
\hline $\mathrm{Ni@3D-(N)GFs}$ & $\mathrm{Ni}$ & $2-4$ & 41.7 & [67] \\
\hline p(HEMA)-Co & Co & - & 3.8 & {$[81]$} \\
\hline $\mathrm{p}(\mathrm{HEMA})-\mathrm{Ni}$ & $\mathrm{Ni}$ & - & 0.8 & - \\
\hline $\mathrm{p}(\mathrm{HEMA})-\mathrm{Cu}$ & $\mathrm{Cu}$ & - & 1.1 & - \\
\hline $\mathrm{p}(\mathrm{SPM})-\mathrm{Co}$ & Co & - & 5.8 & {$[82]$} \\
\hline $\mathrm{p}(\mathrm{SPM})-\mathrm{Ni}$ & $\mathrm{Ni}$ & - & 3.8 & - \\
\hline $\mathrm{p}(\mathrm{SPM})-\mathrm{Cu}$ & $\mathrm{Cu}$ & - & 1.8 & - \\
\hline $\mathrm{p}(\mathrm{VPA})-\mathrm{Co}$ & Co & - & 7.7 & {$[85]$} \\
\hline $\mathrm{p}(\mathrm{VPA})-\mathrm{Ni}$ & $\mathrm{Ni}$ & - & 3.6 & - \\
\hline $\mathrm{p}(\mathrm{VPA})-\mathrm{Cu}$ & $\mathrm{Cu}$ & - & 1.1 & - \\
\hline Co-MOF & Co & $<10$ & 20.8 & [98] \\
\hline Ni-ZIF-8 & $\mathrm{Ni}$ & 2.7 & 14.2 & [99] \\
\hline Pt@MIL-101(Cr) & $\mathrm{Pt}$ & $1.2-3$ & 446.4 & {$[46]$} \\
\hline AuNi@MIL-101(Cr) & $\mathrm{AuNi}$ & $2.9-3.4$ & 66.2 & {$[103]$} \\
\hline AuCo@MIL101(Cr) & $\mathrm{AuCo}$ & 1.8 & 23.5 & {$[102]$} \\
\hline
\end{tabular}

\section{Nanostructured Materials}

An efficient approach to tune the reactivity of a catalytic material is nanostructuring. Nanodesign of materials, with hierarchical nanometric channels [104], containing both interconnected macroporous and mesoporous structures, is under investigation for a wide range of applications in different fields [105,106]. Nanostructured hollow spheres have attracted more and more attention in recent years, because of their special structures and unique properties [107]. For example, the void space in the hollow structure has been used to show the particle's ability to withstand the cyclic change in volume [108], modulate refractive index [109], increase active area for catalysis and encapsulate sensitive materials (e.g., drugs, cosmetics and DNA) [110].

$\mathrm{Ni}_{1-x} \mathrm{Pt}_{x}$ hollow spheres were synthesized through a template route by a replacement reaction using poly(styrene-co-methacrylic acid) (PSA) spheres (ca. $240 \mathrm{~nm}$ ) as sacrificial templates [34]. Ni is first deposited on the surface of the PSA spheres and $\mathrm{Ni}^{2+}$ is reduced by sodium borohydride. The formation of $\mathrm{Ni}_{1-x} \mathrm{Pt}_{x}$ is attained through the replacement reaction between $\mathrm{K}_{2} \mathrm{PtCl}_{6}$ and $\mathrm{Ni}$, where the driving force comes from the large standard reduction potential gap between $\mathrm{Ni}^{2+} / \mathrm{Ni}$ and $\mathrm{PtCl}_{6}{ }^{-} / \mathrm{Pt}$ redox pairs. After the partial consumption of $\mathrm{Ni}$, the resultant $\mathrm{Ni}_{1-x} \mathrm{Pt}_{x}$-PSA core-shell structures are dispersed in a toluene solution to dissolve the PSA template cores, resulting in the formation of $\mathrm{Ni}_{1-x} \mathrm{Pt}_{x}$ metallic alloy hollow spheres. Pt and Ni atoms are distributed homogeneously and randomly at the Ni position. Both complete 
and broken hollow spheres are obtained. The wall thickness of the hollow sphere is $20-40 \mathrm{~nm}$ and the porous shell consists of smaller nanoparticles and nanowhiskers. The as-synthesized alloy hollow sphere catalysts, treated by filtering and washing, can be repeatedly utilized with no significant catalytic deactivation in the hydrolysis experiment. The activation energy of the hydrolysis of ammonia borane is determined to be $30 \mathrm{~kJ} \mathrm{~mol}^{-1}$ for $\mathrm{Ni} 0.88 \mathrm{Pt}_{0.12}$, respectively. The amount of hydrogen generated by $\mathrm{Ni} 0.88 \mathrm{Pt}_{0.12}$ hollow spheres increases nearly linearly with time before the hydrolysis reaction approaches its end, indicating an example of quasi zero-order kinetics.

Hollow nickel nanospheres with an average diameter of 170-450 nm and an average shell thickness of 55-60 nm were obtained by the solvothermal method at $423 \mathrm{~K}$ adjusting volume ratios of ethyl alcohol/ethylenediamine [111]. At the ratio of 4:6, the nickel hollow nanospheres are relatively uniform. When the ratio reaches 5:5, the uniformity of nickel hollow nanospheres becomes worse, and lots of large nickel particles were also formed. At the lower temperature of $393 \mathrm{~K}$, uniform nickel spheres without obvious shells were obtained. While at a higher temperature of $453 \mathrm{~K}$, besides the formation of $\mathrm{Ni}$ hollow spheres, aggregated Ni particles can also be formed and the average diameter of the nickel hollow spheres was also increased. The average size of the crystallized nanoparticles including the hollow spheres is $25-30 \mathrm{~nm}$. $\mathrm{Ni}^{2+}$ cations in solution reacted with excess ethylenediamine to form a relatively stable structure of the $\left[\mathrm{Ni}(\mathrm{en})_{3}\right]^{2+}$ complex, which cannot be reduced by sodium borohydride directly. The Ni/Pt hollow bimetallic nanospheres were also synthesized through the replacement reaction by using the as synthesized hollow nickel nanospheres as sacrificial templates. The average diameter and wall thickness of the Ni/Pt hollow bimetallic nanospheres are $250 \mathrm{~nm}$ and $40-55 \mathrm{~nm}$, respectively. The rate of hydrogen generation on the molar ratio of $85: 15$ of $\mathrm{Ni} / \mathrm{Pt}$ hollow bimetallic nanospheres reaches $5920 \mathrm{~mL}-\mathrm{H}_{2}$ g-cat. $^{-1} \mathrm{~min}^{-1}$.

Spherical particles of silica-nickel composite with hollow feature were obtained by sol-gel based method using PS templates [112-115]. There are two main peaks at around 300 and $680 \mathrm{~nm}$ in the particle size distribution profile of the hollow spheres prepared with $\mathrm{Si}+\mathrm{Ni}$ content $=1.06 \times 10^{-3} \mathrm{~mol}$. The peak at around $300 \mathrm{~nm}$ in the profile of the hollow spheres prepared $\mathrm{Si}+\mathrm{Ni}$ content $=3.19-10.64 \times 10^{-3} \mathrm{~mol}$ is narrower and larger than that in the profile of the hollow spheres prepared with $\mathrm{Si}+\mathrm{Ni}$ content $=1.06 \times 10^{-3} \mathrm{~mol}$, while the number of $680 \mathrm{~nm}$ particles drastically decreases with increase of $\mathrm{Si}+\mathrm{Ni}$ content, indicating that homogeneity of the hollow silica-nickel composite spheres increases with the increase of $\mathrm{Si}+\mathrm{Ni}$ content. The evolution of the molar ratios of the hydrolytically generated hydrogen to the initial ammonia borane, 2.3-2.4, was finished from 32-18 $\mathrm{min}$ in the presence of hollow silica-nickel composite spheres prepared with $\mathrm{Si}+\mathrm{Ni}$ content $=1.06-10.64 \times 10^{-3}$ mol. Clustered nickel species in hollow silica-nickel composite spheres increase with increase of $\mathrm{Si}+\mathrm{Ni}$ content, and more reducible nickel species exist in the hollow spheres prepared with higher $\mathrm{Si}+\mathrm{Ni}$ content. The stirring procedure in toluene is effective for reducing the amount of residual PS templates. The molar ratios of the hydrolytically generated hydrogen to the initial ammonia borane improved up to 2.6 after $22 \mathrm{~min}$. The activation energies were $44-54 \mathrm{~kJ} \mathrm{~mol}^{-1}$ for the hollow spheres.

The wall thickness of hollow silica-zirconia composite spheres ( $c a$. 200-300 nm diameter) was controlled by adjusting the amount of polystyrene template suspension from 2.0-17.5 nm [116]. The molar ratios of hydrolytically generated hydrogen to the initial ammonia borane in the presence of hollow silica-zirconia composite spheres with wall thickness from 17.5-2.0 nm are from 0.5-2.0. 
With decrease of wall thickness of the hollow spheres, both the specific surface area of the hollow spheres and the molar ratio of hydrolytically generated hydrogen to the initial ammonia borane in the presence of the hollow spheres increase. The molar ratio increases four times with the specific surface area increasing two times, indicating that the factors other than specific surface area can influence the catalytic activity of the hollow silica-zirconia composite spheres. The primary particles may form layer-like structures in the wall of hollow silica-zirconia composite spheres with the number of layers depending on the wall thickness.

Hollow silica-alumina composites were obtained by the same method using polystylene templates with and without calcination $[117,118]$. The calcination condition significantly influenced the morphology and activity for hydrolysis of ammonia borane, and homogeneity of the hollow spheres played an important role. Homogeneous hollow composite spheres were obtained upon calcination at $873 \mathrm{~K}$. The molar ratios of hydrolytically generated hydrogen to the initial ammonia borane were 2.6 for $12 \mathrm{~min}$, respectively. The amount of Brønsted acid sites of the hollow spheres had a significant impact on their activity.

Hollow silica-alumina composite spheres with diameters of 200-300 nm were also prepared by the same method using $\mathrm{L}(+)$-arginine as a promoter of the sol-gel reaction [119]. The wall thickness of the samples prepared using L(+)-arginine and 7.5, 15.0, $30.0 \mathrm{~g}$ of PS template suspension were 50.0, 30.0 , and $20.0 \mathrm{~nm}$, respectively. The BET surface area and pore volume of the hollow spheres depend on the shell thickness; however, across all the samples, the average pore size was the same. Almost all the pores in the hollow spheres prepared using $\mathrm{L}(+)$-arginine are micropores and mesopores, and a narrower pore size distribution is observed for the hollow spheres prepared using $\mathrm{L}(+)$-arginine than in the hollow spheres prepared using conventional ammonia. The molar ratio of hydrolytically generated hydrogen to the initial ammonia borane in the presence of hollow spheres prepared using $\mathrm{L}(+)$-arginine with wall thickness $=50.0,30.0,20.0 \mathrm{~nm}$, and hollow spheres prepared using ammonia with wall thickness $=20 \mathrm{~nm}$ are $0.9,2.4,2.5$, and 2.3 for $4,5,7$, and $13 \mathrm{~min}$, respectively. Dispersion of the primary particles of the hollow spheres prepared using $\mathrm{L}(+)$-arginine is higher and/or the primary particles are well-ordered compared with the hollow spheres prepared using ammonia (Figure 4).

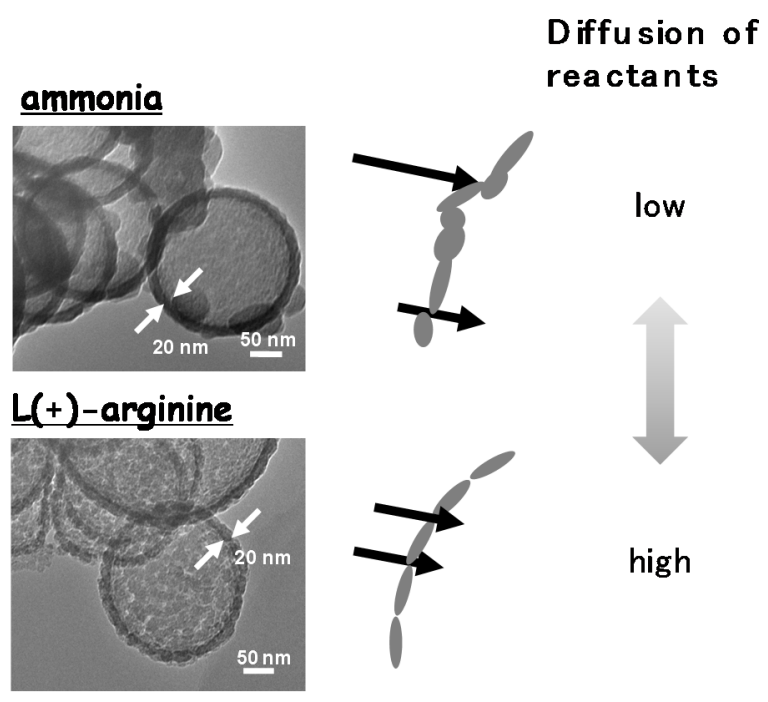

Figure 4. Difference in morphology of hollow silica-alumina composite spheres prepared using ammonia and L(+)-arginine [119]. 
Porous nanowires have attracted a lot of attention because they present the advantages of both 1D nanostructures and high surface area materials. Co nanowires with highly ordered connected macroporosity were obtained by combining self-assembly of polystyrene spheres, a hard templating, together with electrodeposition [120]. The electrodeposition of Co inside the membrane channels followed by polycarbonate membrane and sphere elimination creates a close-packed array of aligned and monodispersed porous nanowires. The as-produced nanowires show a uniform radius $(r=500 \mathrm{~nm})$, which matches that of the polycarbonate membrane channels. 3D ordered macropores are formed inside the submicron wire structures as the replication of the $100 \mathrm{~nm}$ radius ordered PS spheres. Smaller holes appeared to connect the macropores; these holes result from the contacts between the original polystyrene spheres. In addition, the macropores are all connected together with holes. In addition, the nanowire diameter $(100-2500 \mathrm{~nm})$, the macropore sizes and the surface areas can be tuned over a wide range using polycarbonate membranes and polystyrene spheres with different radii (35-500 nm). The nanowires totally hydrolyze ammonia borane within $90 \mathrm{~min}$ whereas with the nonporous nanowires the conversion reaches only $33 \%$. Hydrogen generation rates of $c a .3 .4$ and $0.5 \mathrm{~mL} \mathrm{~min}^{-1}$ were calculated, respectively. With the decrease of diameter of PS spheres, the hydrogen generation rate decreased.

Table 2 lists TOF of various catalysts discussed in this section. From this table, metal based catalysts display relatively high activity. The activity depends on several factors such as compositions, morphology, and homogeneity of the nanostructured materials.

Table 2. TOF of various catalysts.

\begin{tabular}{cccc}
\hline Catalysts & Active Species & TOF $\left(\mathbf{m o l}_{-} \mathbf{H}_{\mathbf{2}} \mathbf{~ m i n}^{-\mathbf{1}}\right.$ mol-Active Species $\left.^{-\mathbf{1}}\right)$ & Ref. \\
\hline Hollow Ni-Pt spheres & $\mathrm{Ni}-\mathrm{Pt}$ bimetal & 19.2 & {$[111]$} \\
Hollow $\mathrm{SiO}_{2}-\mathrm{Ni}$ spheres & $\mathrm{Ni}$ & 3.8 & {$[114]$} \\
Hollow $\mathrm{SiO}_{2}-\mathrm{Al}_{2} \mathrm{O}_{3}$ spheres & $\mathrm{SiO}_{2}-\mathrm{Al}_{2} \mathrm{O}_{3}$ & 0.01 & {$[119]$} \\
$\mathrm{Co} \mathrm{nanowire}$ & $\mathrm{Co}$ & 0.9 & {$[120]$} \\
\hline
\end{tabular}

\section{Conclusions}

The present review briefly surveys porous materials for hydrolytic dehydrogenation of ammonia borane. We mainly discussed porous materials as support materials for active species and as nanostructured catalysts. These materials are effective not only in increasing the number of active sites by controlling particle size and improving the durability by confining and/or protecting the active species in micropores or mesopores, but also control of diffusion of reactants and/or by-products by controlling pore sizes. TOF of various catalysts appear to depend not only on the particle size, but also on other factors such as the particle dispersion, and metal-support interaction. Effective porous materials with high activity are MOF, zeolite, and graphene nanosheets because uniform distribution of metal nanoparticles without aggregation after catalysis confirms the advantage of metal nanoparticles within the matrix materials. Metal-support interactions between active metal species and porous materials play important roles not only in the catalytic activity but also in immobilization of active metal species. These results bring to light new opportunities in the development of high performance heterogeneous catalysts by using functionalized cavities of porous materials as hosts for ultrafine nanoparticles. Among nanostructured materials, metal based nanostructured catalysts display high activity. The activity depends on several factors such as compositions, morphology, homogeneity of their nanostructure, and so on. 
Considering their practical use, it is required for these materials to increase their activity even in solution with a high concentration of reactants and/or by-products. The influence is probably reduced by controlling the diffusion rate of the reactants and/or by-products through pores of the catalyst materials. Controlling not only size of the materials' pores but also fabricating well-ordered pores can also be important factors to control the diffusion rate of the reactants and/or by-products.

\section{Acknowledgments}

We would like to acknowledge College of Science and Technology, Nihon University for its support.

\section{Author Contributions}

T. Umegaki wrote the paper and discussed about the referred studies with Q. Xu and Y. Kojima.

\section{Conflicts of Interest}

The authors declare no conflict of interest.

\section{References}

1. Schlapbach, L.; Zuttel, A. Hydrogen-storage materials for mobile applications. Nature 2001, 414, 353-358.

2. Siblerud, R. Our Future is Hydrogen: Energy, Environment, and Economy; New Science Publications: Wellington, FL, USA, 2001.

3. Barreto, L.; Makihira, A.; Riahi, K. The hydrogen economy in the 21st century: A sustainable development scenario. Int. J. Hydrogen Energy 2003, 28, 267-284.

4. Van den Berg, A.W.C.; Arean, C.O. Materials for hydrogen storage: Current research trends and perspectives. Chem. Commun. 2008, 48, 668-681.

5. Holladay, J.D.; Hu, J.; King, D.L.; Wang, Y. An overview of hydrogen production technologies. Catal. Today 2009, 139, 244-260.

6. Moriarty, P.; Honnery, D. Hydrogen's role in an uncertain energy future. Int. J. Hydrogen Energy 2009, 34, 31-39.

7. Kelly, N.A.; Gibson, T.L.; Cai, M.; Spearot, J.A.; Ouwerkerk, D.B. Development of a renewable hydrogen economy: Optimization of existing technologies. Int. J. Hydrogen Energy 2010, 35, 892-899.

8. Tiwari, A.; Pandey, A. Cyanobacterial hydrogen production-A step towards clean environment. Int. J. Hydrogen Energy 2012, 37, 139-150.

9. Wu, C.; Zhang, H.M.; Yi, B.L. Recent advances in hydrogen generation with chemical methods. Prog. Chem. 2005, 17, 423-429.

10. Yamada, O. Generation of hydrogen gas by reforming biomass with superheated steam. Thin Solid Films 2006, 509, 207-211.

11. Satyapala, S.; Petrovic, J.; Read, C.; Thomas, G.; Ordaz, G. The U.S. Department of energy's national hydrogen storage project: Progress towards meeting hydrogen-powered vehicle requirements. Catal. Today 2007, 120, 246-256. 
12. Stephens, F.H.; Pons, V.; Baker, R.T. Ammonia-borane: The hydrogen source par excellence? Dalton Trans. 2007, 25, 2613-2626.

13. Xu, Q.; Chandra, M. A portable hydrogen generation system: Catalytic hydrolysis of ammonia-borane. J. Alloys Compd. 2007, 446-447, 729-732.

14. Biniwale, R.B.; Rayalu, S.; Devotta, S.; Ichikawa, M. Chemical hydrides: A solution to high capacity hydrogen storage and supply. Int. J. Hydrogen Energy 2008, 33, 360-365.

15. Hamilton, C.W.; Baker, R.T.; Staubitz, A.; Manners, I. B-N compounds for chemical hydrogen storage. Chem. Soc. Rev. 2009, 38, 279-293.

16. Wang, P.; Kang, X.D. Hydrogen-rich boron-containing materials for hydrogen storage. Dalton Trans. 2008, 40, 5400-5413.

17. Umegaki, T.; Yan, J.M.; Zhang, X.B.; Shioyama, H.; Kuriyama, N.; Xu, Q. Boron- and nitrogen-based chemical hydrogen storage materials. Int. J. Hydrogen Energy 2009, 34, 2303-2311.

18. Sanyal, U.; Demirci, U.B.; Jagirdar, B.R.; Miele, P. Hydrolysis of ammonia borane as a hydrogen source: Fundamental issues and potential solutions towards implementation. ChemSusChem 2011, 4, 1731-1739.

19. Yadav, M.; Xu, Q. Liquid-phase chemical hydrogen storage materials. Energy Environ. Sci. 2012, 5, 9698-9725.

20. Lu, Z.-H.; Xu, Q. Recent progress in boron- and nitrogen-based chemical storage. Funct. Mater. Lett. 2012, 5, 1230001:1-1230001:9.

21. Xu, Q.; Chandra, M. Catalytic activities of non-noble metals for hydrogen generation from aqueous ammonia-borane at room temperature. J. Power Sources 2006, 163, 364-370.

22. Patel, N.; Guella, G.; Kale, A.; Miotello, A.; Patton, B.; Zanchetta, C.; Mirenghi, L.; Rotolo, R. Thin films of Co-B prepared by pulsed laser deposition as efficient catalysts in hydrogen producing reactions. Appl. Catal. A 2007, 323, 18-24.

23. Chandra, M.; Xu, Q. Room temperature hydrogen generation from aqueous ammonia-borane using noble metal nanoclusters as highly active catalysts. J. Power Sources 2007, 168, 135-142.

24. Yan, J.M.; Zhang, X.B.; Han, S.; Shioyama, H.; Xu, Q. Iron nanoparticle-catalyzed hydrolytic dehydrogenation of ammonia borane for chemical hydrogen storage. Angew. Chem. Int. Ed. 2008, 47, 2287-2289.

25. Kalidindi, S.B.; Indirani, M.; Jagirdar, B.R. First row transition metal ion-assisted ammonia-borane hydrolysis for hydrogen generation. Inorg. Chem. 2008, 47, 7424-7429.

26. Diwan, M.; Hanna, D.; Varma, A. Method to release hydrogen from ammonia borane for portable fuel cell applications. Int. J. Hydrogen Energy 2010, 35, 577-584.

27. Yan, J.M.; Zhang, X.B.; Akita, T.; Haruta, M.; Xu, Q. One-step seeding growth of magnetically recyclableAu@Co core-shell nanoparticles: Highly efficient catalyst for hydrolytic dehydrogenation of ammonia borane. J. Am. Chem. Soc. 2010, 132, 5326-5327.

28. Figen, A.K.; Pişkin, M.B.; Coşkuner, B.; İmamoğlu, V. Synthesis, structural characterization, and hydrolysis of ammonia borane $\left(\mathrm{NH}_{3} \mathrm{BH}_{3}\right)$ as a hydrogen storage carrier. Int. J. Hydrogen Energy 2013, 38, 16215-16228.

29. Cao, N.; Hua, K.; Luo, W.; Cheng, G. RuCu nanoparticles supported on graphene: A highly efficient catalyst for hydrolysis of ammonia borane. J. Alloys Compd. 2014, 590, 241-246. 
30. Veeraraghavan, P.; Gagare, P.D. Preparation of ammonia borane in high yield and purity, methanolysis and regeneration. Inorg. Chem. 2007, 46, 7810-7817.

31. Rakap, M.; Özkar, S. Zeolite confined palladium(0) nanoclusters as effective and reusable catalyst for hydrogen generation from the hydrolysis of ammonia borane. Int. J. Hydrogen Energy 2010, $35,1305-1312$.

32. Chandra, M.; Xu, Q. Dissociation and hydrolysis of ammonia-borane with solid acids and carbon dioxide: An efficient hydrogen generation system. J. Power Sources 2006, 159, 855-860.

33. Chandra, M.; Xu, Q. A high-performance hydrogen generation system: Transition metal-catalyzed dissociation and hydrolysis of ammonia-borane. J. Power Sources 2006, 156, 190-194.

34. Cheng, F.Y.; Ma, H.; Li, Y.M.; Chen, J. Ni ${ }_{1-x} \mathrm{Pt}_{x}(x=0-0.12)$ hollow spheres as catalysts for hydrogen generation from ammonia borane. Inorg. Chem. 2007, 46, 788-794.

35. Kalidindi, S.B.; Sanyal, U.; Jagirdar, B.R. Nanostructured $\mathrm{Cu}$ and $\mathrm{Cu} @ \mathrm{Cu}_{2} \mathrm{O}$ core shell catalysts for hydrogen generation from ammonia-borane. Phys. Chem. Chem. Phys. 2008, 10, 5870-5874.

36. Zahmaklran, M.; Özkar, S. Zeolite framework stabilized rhodium(0) nanoclusters catalyst for the hydrolysis of ammonia-borane in air: Outstanding catalytic activity, reusability and lifetime. Appl. Catal. B 2009, 89, 104-110.

37. Umegaki, T.; Yan, J.M.; Zhang, X.B.; Shioyama, H.; Kuriyama, N.; Xu, Q. Preparation and catalysis of poly( $N$-vinyl-2-pyrrolidone) (PVP) stabilized nickel catalyst for hydrolytic dehydrogenation of ammonia borane. Int. J. Hydrogen Energy 2009, 34, 3816-3822.

38. Durap, F.; Zahmakiran, M.; Özkar, S. Water soluble laurate stabilized ruthenium(0) nanoclusters catalyst for hydrogen generation from the hydrolysis of ammonia-borane: High activity and long lifetime. Int. J. Hydrogen Energy 2009, 34, 7223-7230.

39. Basu, S.; Brockman, A.; Gagare, P.; Zheng, Y.; Ramachandran, P.V.; Delgass, W.N.; Gore, J.P. Chemical kinetics of Ru-catalyzed ammonia borane hydrolysis. J. Power Sources 2009, 188, $238-243$.

40. Umegaki, T.; Yan, J.M.; Zhang, X.B.; Shioyama, H.; Kuriyama, N.; Xu, Q. Hollow Ni-SiO 2 nanosphere-catalyzed hydrolytic dehydrogenation of ammonia borane for chemical hydrogen storage. J. Power Sources 2009, 191, 209-216.

41. Yan, J.M.; Zhang, X.B.; Han, S.; Shioyama, H.; Xu, Q. Magnetically recyclable Fe-Ni alloy catalyzed dehydrogenation of ammonia borane in aqueous solution under ambient atmosphere. J. Power Sources 2009, 194, 478-481.

42. Brockman, A.; Zheng, Y.; Gore, J. A study of catalytic hydrolysis of concentrated ammonia borane solutions. Int. J. Hydrogen Energy 2010, 35, 7350-7356.

43. Metin, Ö.; Mazumder, V.; Özkar, S.; Sun, S.S. Monodisperse nickel nanoparticles; and their catalysis in hydrolytic dehydrogenation of ammonia borane. J. Am. Chem. Soc. 2010, 132, 1468-1469.

44. Sun, D.H.; Mazumder, V.; Metin, O.; Sun, S.H. Catalytic hydrolysis of ammonia borane via cobalt palladium nanoparticles. ACS Nano 2011, 8, 6458-6464.

45. Li, P.Z.; Aijaz, A.; Xu, Q. Highly dispersed surfactant-free nickel nanoparticles and their remarkable catalytic activity in the hydrolysis of ammonia borane for hydrogen generation. Angew. Chem. Int. Ed. 2012, 51, 6753-6756. 
46. Aijaz, A.; Karkamkar, A.; Choi, Y.J.; Tsumori, N.; Rönnebro, E.; Autrey, T.; Shioyama, H.; Xu, Q. Immobilizing highly catalytically active Pt Nanoparticles inside the pores of metal-organic framework: A double solvents approach. J. Am. Chem. Soc. 2012, 134, 13926-13929.

47. Luo, Y.C.; Liu, Y.H.; Hung, Y.; Liu, X.Y.; Mou, C.Y. Mesoporous silica supported cobalt catalysts for hydrogen generation in hydrolysis of ammonia borane. Int. J. Hydrogen Energy 2013, 38, 7280-7290.

48. Seven, F.; Sahiner, N. Metal ion-imprinted hydrogel with magnetic properties and enhanced catalytic performances in hydrolysis of $\mathrm{NaBH}_{4}$ and $\mathrm{NH}_{3} \mathrm{BH}_{3}$. Int. J. Hydrogen Energy 2013, 38, $15275-15284$.

49. Hoa, M.L.K.; Lu, M.H.; Zhang, Y. Preparation of porous materials with ordered hole structure. Adv. Colloid Interface Sci. 2006, 121, 9-23.

50. Gokmen, M.T.; Prez, F.E.D. Porous polymer particles-A comprehensive guide to synthesis, characterization, functionalization and application. Prog. Polym. Sci. 2012, 37, 365-405.

51. Rakap, M.; Özkar, S. Hydroxyapatite-supported cobalt( $(0)$ nanoclusters as efficient and cost-effective catalyst for hydrogen generation from the hydrolysis of both sodium borohydride and ammonia-borane. Catal. Today 2012, 183, 17-25.

52. Doner, A.; Karci, I.; Kardas, G. Effect of C-felt supported Ni, Co and NiCo catalysts to produce hydrogen. Int. J. Hydrogen Energy 2012, 37, 9470-9476.

53. Seidel, A.; Loos, J.; Boddenberg, B. Copper nanoparticles in zeolite Y. J. Mater. Chem. 1999, 9, 2495-2498.

54. Tang, Q.; Zhang, Q.; Wang, P.; Wang, Y.; Wan, H. Characterizations of cobalt oxide nanoparticles within faujasite zeolites and the formation of metallic cobalt. Chem. Mater. 2004, 16, 1967-1976.

55. Patel, N.; Fernandes, R.; Gupta, S.; Edla, R.; Kothari, D.C.; Miotello, A. Co-B catalyst supported over mesoporous silica for hydrogen production by catalytic hydrolysis of Ammonia Borane: A study on influence of pore structure. Appl. Catal. B 2013, 140-141, 125-132.

56. Rakap, M.; Özkar, S. Hydrogen generation from the hydrolysis of ammonia-borane using intrazeolite cobalt(0) nanoclusters catalyst. Int. J. Hydrogen Energy 2010, 35, 3341-3346.

57. Eom, K.S.; Cho, K.W.; Kwon, H.S. Hydrogen generation from hydrolysis of $\mathrm{NH}_{3} \mathrm{BH}_{3}$ by an electroplated Co-P catalyst. Int. J. Hydrogen Energy 2010, 35, 181-186.

58. Dai, H.B.; Gao, L.L.; Liang, Y.; Kang, X.D.; Wang, P. Promoted hydrogen generation from ammonia borane aqueous solution using cobalt-molybdenum-boron/nickel foam catalyst. J. Power Sources 2010, 195, 307-312.

59. Patel, N.; Femandes, R.; Edla, R.; Lihitkar, P.B.; Kothari, D.C.; Miotello, A. Superior hydrogen production rate by catalytic hydrolysis of ammonia borane using $\mathrm{Co}-\mathrm{B}$ nanoparticles supported over mesoporous silica particles. Catal. Commun. 2012, 23, 39-42.

60. Patel, N.; Fernandes, R.; Guella, G.; Miotello, A. Nanoparticle assembled Co-B thin film for the hydrolysis of ammonia borane: A highly active catalyst for hydrogen production. Appl. Catal. B 2010, 95, 137-143.

61. Ossi, P.M.; Bottani, C.E.; Miotello, A. Pulsed-laser deposition of carbon: From DLC to cluster-assembled films. Thin Solid Films 2005, 482, 2-8. 
62. Patel, N.; Fernandes, R.; Santini, A.; Miotello, A. Co-B nanoparticles supported on carbon film synthesized by pulsed laser deposition for hydrolysis of ammonia borane. Int. J. Hydrogen Energy 2012, 37, 2007-2013.

63. Fernandes, R.; Patel, N.; Miotello, A.; Jaiswal, R.; Kothari, D.C. Dehydrogenation of ammonia borane with transition metal-doped Co-B alloy catalysts. Int. J. Hydrogen Energy 2012, 37, 2397-2406.

64. Yang, J.; Cheng, F.; Liang, J.; Chen, J. Hydrogen generation by hydrolysis of ammonia borane with a nanoporous cobalt-tungsten-boron-phosphorous catalyst supported on Ni foam. Int. J. Hydrogen Energy 2011, 36, 1411-1417.

65. Zahmakıran, M.; Durap, F.; Ozkar, S. Zeolite confined copper(0) nanoclusters as cost-effective and reusable catalyst in hydrogen generation from the hydrolysis of ammonia-borane. Int. J. Hydrogen Energy 2010, 35, 187-197.

66. Zahmakiran, M. Preparation and characterization of LTA-type zeolite framework dispersed ruthenium nanoparticles and their catalytic application in the hydrolytic dehydrogenation of ammonia-borane for efficient hydrogen generation. Mater. Sci. Eng. B 2012, 177, 606-613.

67. Mahyari, M.; Shaabani, A. Nickel nanoparticles immobilized on three-dimensional nitrogen-doped graphene as a superb catalyst for the generation of hydrogen from the hydrolysis of ammonia borane. J. Mater. Chem. A 2014, 2, 16652-16659.

68. Sahiner, N. Soft and flexible hydrogel templates of different sizes and various functionalities for metal nanoparticle preparation and their use in catalysis. Prog. Polym. Sci. 2013, 38, 1329-1356.

69. Guizard, C.; Bac, A.; Barboiu, M.; Hovnanian, N. Hybrid organic-inorganic membranes with specific transport properties: Applications in separation and sensors technologies. Sep. Purif. Technol. 2001, $25,167-180$.

70. Lu, Z.H.; Liu, G.J.; Duncan, S. Poly(2-hydroxyethyl acrylate-co-methyl acrylate) $/ \mathrm{SiO}_{2} / \mathrm{TiO}_{2}$ hybrid membranes. J. Membr. Sci. 2003, 221, 113-122.

71. Chiang, P.C.; Whang, W.T.; Tsai, M.H. Physical and mechanical properties of polyimide/titania hybrid films. Thin Solid Films 2004, 447-448, 359-364.

72. Yu, L.Y.; Xu, Z.L.; Shen, H.M.; Yang, H. Preparation and characterization of PVDF-SiO 2 composite hollow fiber UF membrane by sol-gel method. J. Membr. Sci. 2009, 337, 257-265.

73. Oha, J.K.; Leea, D.I.; Park, J.M. Biopolymer-based microgels/nanogels for drug delivery application. Prog. Polym. Sci. 2009, 34, 1261-1282.

74. Chang, C.; Zhang, L. Cellulose-based hydrogels: Present status and application prospects. Carbohydr. Polym. 2011, 84, 40-53.

75. Jesionowski, T.; Krysztafkiewicz, A. Preparation of the hydrophilic/hydrophobic silica particles. Colloid Surf. A 2002, 207, 49-58.

76. Schexnailder, P.; Schmidt, G. Nanocomposite polymer hydrogels. Colloid Polym. Sci. 2009, 287, $1-11$.

77. Tuzmen, N.; Kalburcu, T.; Denizli, A. Immobilization of catalase via adsorption onto metal-chelated affinity cryogels. Process Biochem. 2012, 47, 26-33.

78. Dragan, E.S.; Loghin, D.F.A. Enhanced sorption of methylene blue from aqueous solutions by semi-IPN composite cryogels with anionically modified potato starch entrapped in PAAm matrix. Chem. Eng. J. 2013, 234, 211-222. 
79. Tuncaboylu, D.C.; Okay, O. Hierarchically macroporous cryogels of polyisobutylene and silica nanoparticles. Langmuir 2010, 26, 7574-7581.

80. Bilici, C.; Karayel, S.; Demir, T.T.; Okay, O. Self-oscillating pH responsive cryogels as possible candidates of soft materials for generating mechanical energy. J. Appl. Polym. Sci. 2010, 118, 2981-2988.

81. Seven, F; Sahiner, N. Superporous P(2-hydroxyethyl methacrylate) cryogel-M (M: Co, Ni, Cu) composites as highly effective catalysts in $\mathrm{H}_{2}$ generation from hydrolysis of $\mathrm{NaBH}_{4}$ and $\mathrm{NH}_{3} \mathrm{BH}_{3}$. Int. J. Hydrogen Energy 2014, 39, 15455-15463.

82. Yildiz, S.; Aktas, N.; Sahiner, N. Metal nanoparticle-embedded super porous poly(3-sulfopropyl methacrylate) cryogel for $\mathrm{H}_{2}$ production from chemical hydride hydrolysis. Int. J. Hydrogen Energy 2014, 39, 14690-14700.

83. Sahiner, N.; Turhan, T. Lyon LAILC. (ionic liquid colloids) based on p(4-VP) (poly(4-vinyl pyridine)) microgels: Synthesis, characterization and use in hydrogen production. Energy 2014, 66, 256-263.

84. Sahiner, N.; Sagbas, S. The preparation of poly(vinyl phosphonic acid) hydrogels as new functional materials for in situ metal nanoparticles. Colloid Surf. A 2013, 418, 76-83.

85. Sahiner, N.; Sagbas, S. The use of poly(vinyl phosphonic acid) microgels for the preparation of inherently magnetic Co metal catalyst particles in hydrogen production. J. Power Sources 2014, 246, 55-62.

86. Eddaoudi, M.; Kim, J.; Rosi, N.; Vodak, D.; Wachter, J.; O’Keeffe, M.; Yaghi, O.M. Systematic design of pore size and functionality in isoreticular MOFs and their application in methane storage. Science 2002, 295, 469-472.

87. Ma S.; Zhou, H.C. A metal-organic framework with entatic metal centers exhibiting high gas adsorption affinity. J. Am. Chem. Soc. 2006, 128, 11734-11735.

88. Ghosh, S.K.; Bureekaew S.; Kitagawa. S. A dynamic, isocyanurate-functionalized porous coordination polymer. Angew. Chem. Int. Ed. 2008, 47, 3403-3406.

89. Li, Y.Q.; Xie, L.; Li, Y.; Zheng, J.; Li, X.G. Metal-organic-framework-based catalyst for highly efficient $\mathrm{H}_{2}$ generation from aqueous $\mathrm{NH}_{3} \mathrm{BH}_{3}$ solution. Chem. Eur. J. 2009, 15, 8951-8954.

90. Férey, G.; Serre, C. Large breathing effects in three-demensional porous hybrid matter: Facts, analyses, rules and consequences. Chem. Soc. Rev. 2009, 38, 1380-1399.

91. Jiang, H.L.; Tatsu, Y.; Lu Z.H.; Xu, Q. Non-, micro, and mesoporous metal-organic framework isomers: Reversible transformation, fluorescence sensing, and large molecule separation. J. Am. Chem. Soc. 2010, 132, 5586-5587.

92. Motoyama, S.; Makiura, R.; Sakata, O.; Kitagawa, H. Highly crystalline nanofilm by layering of porphyrin metal-organic framework sheets. J. Am. Chem. Soc. 2011, 133, 5640-5643.

93. Jiang, H.L.; Xu, Q. Porous metal-organic frameworks as platforms for functional applications. Chem. Commun. 2011, 47, 3351-3370.

94. Lu, G.; Li, S.; Guo, Z.; Farha, O.K.; Hauser, B.G.; Qi, X.; Wang, Y.; Wang, X.; Han, S.; Liu, X.; et al. Imparting functionality to a metal-organic framework material by controlled nanoparticle encapsulation. Nat. Chem. 2012, 4, 310-316.

95. Li, S.L.; Xu, Q. Metal-organic frameworks as platforms for clean energy. Energy Environ. Sci. 2013, 6, 1656-1683. 
96. Gu, X.; Lu, Z.-H.; Jiang, H.L.; Akita, T.; Xu, Q. Synergistic catalysis of metal-organic framework-immobilized $\mathrm{Au}-\mathrm{Pd}$ nanoparticles in dehydrogenation of formic acid for chemical hydrogen storage. J. Am. Chem. Soc. 2011, 133, 11822-11825.

97. Zhu, Q.L.; Xu, Q. Metal-organic framework composites. Chem. Soc. Rev. 2014, 43, 5468-5512.

98. Song, P.; Li, Y.; Li, W.; He, B.; Yang, J.; Li, X. A highly efficient Co(0) catalyst derived from metal-organic framework for the hydrolysis of ammonia borane. Int. J. Hydrogen Energy 2011, 36, 10468-10473.

99. Li, P.Z.; Aranishi, K.; Xu, Q. ZIF-8 immobilized nickel nanoparticles: Highly effective catalysts for hydrogen generation from hydrolysis of ammonia borane. Chem. Commun. 2012, 48, 3173-3175.

100. Jiang, H.L.; Xu, Q. Recent progress in synergistic catalysis over heterometallic nanoparticles. J. Mater. Chem. 2011, 21, 13705-13725.

101. Singh, A.K.; Xu, Q. Synergistic catalysis over bimetallic alloy nanoparticles. ChemCatChem 2013, $5,652-676$.

102. Zhu, Q.L.; Li, J.; Xu, Q. Immobilizing metal nanoparticles to metal-organic frameworks with size and location control for optimizing catalytic performance. J. Am. Chem. Soc. 2013, 135, 10210-10213.

103. Li, J.; Zhu, Q.L.; Xu, Q. Highly active AuCo alloy nanoparticles encapsulated in the pore of metal-organic frameworks for hydrolytic dehydrogenation of ammonia borane. Chem. Commun. 2014, 5899-5901.

104. Yuan, Z.Y.; Su, B.L. Insights into hierarchically meso-macroporous structured materials. J. Mater. Chem. 2006, 16, 663-677.

105. Elias, J.; Bechelany, M.; Utke, I.; Erni, R.; Hosseini, D.; Michler, J.; Philippe, L. Urchin-inspired zinc oxide as building blocks for nanostructured solar cells. Nano Energy 2012, 1, 696-705.

106. Marichy, C.; Bechelany, M.; Pinna, N. Atomic layer deposition of nanostructured materials for energy and environmental applications. Adv. Mater. 2012, 24, 1017-1032.

107. Chen, I.H.; Wang, C.C.; Chen, C.Y. Synthesis of mono-disperse hollow nickel spheres with a double shell structure using poly(methyl methacrylate) as a template. Scr. Mater. 2008, 58, 37-40.

108. Xu, S.; Hessel, C.M.; Ren, H.; Yu, R.; Jin, Q.; Yang, M.; Zhao, H.; Wang, D. $\alpha-\mathrm{Fe}_{2} \mathrm{O}_{3}$ multi-shelled hollow microspheres for lithium ion battery anodes with superior capacity and charge retention. Energy Environ. Sci. 2014, 7, 632-637.

109. Dong, Z.; Lai, X.; Halpert, J.E.; Yang, N.; Yi, L.; Zhai, J.; Wang, D.; Tang, Z.; Jiang, L. Accurate control of multishelled $\mathrm{ZnO}$ hollow microspheres for dye-sensitized solar cells with high efficiency. Adv. Mater. 2012, 24, 1046-1049.

110. Lou, X.W.; Archer, L.A.; Yang, Z. Hollow micro-/nanostructures: Synthesis and applications. Adv. Mater. 2008, 20, 3987-4019.

111. Jiao, W.; Hu, X.; Ren, H.; Xu, P.; Yu, R.; Chen, J.; Xing, X. Magnetic Ni and Ni/Pt hollow nanospheres and their catalytic activities for hydrolysis of ammonia borane. J. Mater. Chem. A 2014, 2, 18171-18176.

112. Umegaki, T.; Takei, C.; Xu, Q.; Kojima, Y. Fabrication of hollow metal oxide-nickel composite spheres and their catalytic activity for hydrolytic dehydrogenation of ammonia borane. Int. J. Hydrogen Energy 2013, 38, 1397-1404. 
113. Umegaki, T.; Takei, C.; Watanuki, Y.; Xu, Q.; Kojima, Y. Fabrication of hollow nickel-silica composite spheres using $\mathrm{L}(+)$-arginine and their catalytic performance for hydrolytic dehydrogenation of ammonia borane. J. Mol. Catal. A 2013, 371, 1-7.

114. Umegaki, T.; Seki, A.; Xu, Q.; Kojima, Y. Influence of preparation conditions of hollow silica-nickel composite spheres on their catalytic activity for hydrolytic dehydrogenation of ammonia borane. J. Alloy. Compd. 2014, 588, 615-621.

115. Umegaki, T.; Watanuki, Y.; Xu, Q.; Kojima, Y. Effect of solvents on morphology of hollow nickel-silica composite spheres and their catalytic performance for hydrolytic dehydrogenation of ammonia borane. J. Jpn. Inst. Energy 2014, 93, 703-709.

116. Umegaki, T.; Hosoya, T.; Toyama, N.; Xu, Q.; Kojima, Y. Fabrication of hollow silica-zirconia composite spheres and their activity for hydrolytic dehydrogenation of ammonia borane. J. Alloy. Compd. 2014, 608, 261-265.

117. Toyama, N.; Umegaki, T.; Kojima, Y. Fabrication of hollow silica-alumina composite spheres and their activity for hydrolytic dehydrogenation of ammonia borane. Int. J. Hydrogen Energy 2014, 39, 17136-17143.

118. Toyama, N.; Umegaki, T.; Xu, Q.; Kojima, Y. Control of particle size of hollow silica-alumina composite spheres and their activity for hydrolytic dehydrogenation of ammonia borane. J. Jpn. Inst. Energy 2014, 93, 511-516.

119. Umegaki, T.; Imamura, S.; Toyama, N.; Kojima, Y. Influence of preparation conditions on the morphology of hollow silica-alumina composite spheres and their activity for hydrolytic dehydrogenation of ammonia borane. Microporous Mesoporous Mater. 2014, 196, 349-353.

120. Bechelany, M.; Chaaya, A.A.; Frances, F.; Akdim, O.; Cot, D.; Demirci, U.B.; Miele, P. Nanowires with controlled porosity for hydrogen production. J. Mater. Chem. A 2013, 1, 2133-2138.

(C) 2015 by the authors; licensee MDPI, Basel, Switzerland. This article is an open access article distributed under the terms and conditions of the Creative Commons Attribution license (http://creativecommons.org/licenses/by/4.0/). 